\title{
Gastrointestinal Hemorrhage
}

National Cancer Institute

\section{Source}

National Cancer Institute. Gastrointestinal Hemorrhage. NCI Thesaurus. Code C48592.

Bleeding originating from any part of the gastrointestinal tract. 